\title{
PASSIVATION OF LOW CARBON STEEL DUE TO CONDUCTING POLYANILINE BASED PAINT
}

\author{
Sunil P. Jagtap ${ }^{1}$ \\ ${ }^{1}$ RMD Sinhgad School of Engineering, Warje, Pune-411058 (M.S.) India \\ drspjagtap@gmail.com
}

\begin{abstract}
Conducting polyaniline powder was synthesized chemically and paints containing conducting polyaniline powder were applied on low carbon steel samples. Corrosion protection performance of the coating in $3.5 \%$ sodium chloride solution up to 48 hours and 120 hours was evaluated by using electrochemical impedance spectroscopy. It has been found that the open circuit potentials of painted steel, after the initial decrease, have been shifted to noble direction. In addition, charge transfer values have been observed to increase due to passivation of steel by PANI-HCl pigment indicating anti corrosive nature of paint.
\end{abstract}

Keywords: Conducting Polyaniline Based Paint; Low Carbon Steel; Corrosion Protection; Impedance Spectroscopy. $* * *$

\section{INTRODUCTION}

Metals and alloys corrode in environments encountered during their use. Corrosion, being an electrochemical phenomenon, can be tackled through the use of electrochemistry and conducting polymers[1].Conducting polymer coating on metals or alloys can be obtained using electrochemical deposition techniques [2, 3]. Although, a lot of work has been carried out on electrochemical deposition of conducting polymer on the active metals like iron and steel in recent years, it is difficult to use this approach on massive engineering structures such as ships and bridges. Therefore chemical synthesis route must be explored and extended towards commercial approach. A. Talo et al. studied polyaniline /epoxy blend coatings on mild steel in $0.6 \mathrm{MNaCl}$ and $0.1 \mathrm{MHCl}$ solutions. In this work, the corrosion protective performance was characterized by a shift of corrosion potential by $500 \mathrm{mV}$ in the noble direction and by a decrease of five orders of magnitude in the redox current [4]. P.C.Deb et al. demonstrated use ofa paint containing polyaniline-hydrochloride as pigment. Painted panels were exposed in weatherometer chamber, humidity cabinet and salt spray chamber and sea water. Potentio dynamic measurements were also made for finding corrosion current, potential and polarization resistance. It has been observed in this work that paints having lower loading of PANI- $\mathrm{HCl}$ ismore effective in corrosion prevention of mild steel in $3.5 \mathrm{wt} \% \mathrm{NaCl}$ [5]. T.K.Rout et al. formulated a coating by dispersing conducting polyaniline powder in a medium oil alkyd resin and evaluated its corrosion resistance. It has been found that the corrosion resistance of PANI coated samples was10-15 times higher than the bare steel. In this work, it was also shown that a continuous charge transfer reaction across the metal- coating interface was responsible for the increase in coating capacitance and decrease in polarization resistance [6]. S.Sathiyanarayanan et al. investigated the corrosion performance of polyaniline pigmented coating on steel by electrochemical impedance spectroscopy in $3 \mathrm{wt} \% \mathrm{NaCl}$ and $0.1 \mathrm{~N} \mathrm{HCl}$ solutions and found out that these coatings were able to protect the steel both in acid and neutral media [7].A.B. Samui et al. incorporated dioctyl phosphate doped polyanline as active pigment in various resins and observed that these paints offered protective performance to mild steel for longer period compared to other resins [8].Jose Ignacio IribarrenLaco et al. studied corrosion protection of steel with thermoplastic coatings and alkyd resins containing polyaniline and showed that the presence of conductive polaniline in alkyd resin improved the corrosion protection performance [9].S. Syed Azim prepared conducting polyaniline- aminotrimethylenephosphonic acid (PANIATMP), dispersed the polymer in epoxy resin. It has been found out that the open circuit potentials for coated steel have been shifted to noble direction after initial delay in the active direction in $3 \mathrm{wt} \% \mathrm{NaCl}$. In addition, the charge transfer resistance values have been found to increase with time due to passivation of steel by PANI- ATMP pigment indicating the protective nature of the coating [10]. S.Touzain et al. used hydrochloride polyaniline powder as a conductive pigment into powder zinc-rich primer formulations in order to enhance the electronic conduction path between zinc particles inside the coating and the steel. The protective properties and electrochemical behavior of coatings were investigated by monitoring the free corrosion potential versus time and by using electrochemical impedance spectroscopy. It has been shown that this coating exhibits good barrier properties in $3 \% \mathrm{NaCl}$ solution[11]. Andrea Kalendova et al. tested four pigments of different morphologies - specularite, goethite, talc and graphite with and without polyaniline phosphate coating obtained by epoxy binders on iron plates. In this work, the corrosion tests were carried out in a condenser chamber with continuous water condensation or humidity with sulphurdioxide and in a salt mist cabinet. It has been observed that polynailine coatings of pigments in all cases 
improved the anticorrosion properties and graphite coated with PANI performed the best among all the formulations [12]. C.Aleman et al. investigated the corrosion protection imparted by epoxy paints modified by the addition of polyanilineemeraldine base and $\mathrm{Zn}_{3}\left(\mathrm{PO}_{4}\right)_{2}$ and observed that epoxy with PANI - emeradline base offered higher protection to mild steel compared to unmodified epoxy paints[13].E.Armelin et al. employed polyanilineemeraldine salt, polyanilineemeraldine base, polyaniline composite black, polypyrrole composite with carbon black and poly (3,4-ethylenedioxythiophene) doped with poly (styrene sulphonate) and found out that corrosion protection to mild steel offered by formulations modified by conducting polymers and especially polynilineemeraldine base was significantly higher than that of the unmodified paint [14]. K.Kamaraj et al. found that the vinyl coating containing benzoate doped polyaniline was able to protect steel in neutral media better than in acid media [15].S.Sathiyanarayanan et al. observed that coatings containing $1 \mathrm{wt} \%$ and $3 \mathrm{wt} \%$ phosphate doped polyaniline and $3 \mathrm{wt} \%$ doped chloride doped polyaniline were highly corrosion resistant in $3 \% \mathrm{NaCl}$ solution [16].S. Sathiyanarayanan studied corrosion protection performance of sulphonate doped polyaniline containing vinyl coatings containing in $0.1 \mathrm{NHCl}$ and $3 \mathrm{wt}$. \% $\mathrm{NaCl}$ by open circuit potential and impedance measurements. The open circuit potential showed that the coatings with polyaniline maintain the potential in the noble range whereas the coatings without polyaniline exhibit potentials in the active range.EIS studies revealed that the sulphonate doped polyanilineis able to protect the steel in acid and in neutral media even after 100 days of exposure [17]. We recently investigated corrosion prevention performance of paint containing polyanilinehydrochloride as pigment by potentiodynamicpolarization studies and observed that $2 \mathrm{wt} \%$ polyaniline- hydrochloride based paint is more effective than paints containing lower loading of PANI- $\mathrm{HCl}$ for corrosion prevention of low carbon steel in $0.1 \mathrm{~N} \mathrm{HCl}$ solution and $3.5 \mathrm{wt} \% \mathrm{NaCl}[18]$. To study long term performance, conducting polyanilinehydrochloride based painted samples were immersed in 3.5 $\% \mathrm{NaCl}$ for 48 hours and 120 hours and the electrochemical investigations are reported in this work.

\section{EXPERIMENTAL}

\subsection{Materials}

Aniline (ARgrade supplied by Loba Chemicals, Colaba,Mumbai -400 005, India) was double distilled prior to use. Chemicals - hydrochloric acid, ammonium persulphate and ammonia solution (AR grade supplied byLoba Chemicals,Colaba, Mumbai- 400 005, India)were used withoutfurther purification.Ingredients - Xylene, titanium dioxide $\left(\mathrm{TiO}_{2}\right)$ and dioctyl phthalate (DOP) (R grade supplied by Loba Chemicals,Colaba, Mumbai- 400 005, India) were used as received.Standard epoxyresin (GY 250 supplied by Huntsman Advanced Materials (India) Pvt Ltd. Andheri (East), Mumbai- 400 093, India) was used as received. Low carbon steel samples (AISI 1015) were purchased from local supplier.

\subsection{Conducting Polyaniline based Paints}

\section{Preparation and its Application}

Conducting Polyaniline was synthesized from aniline in aqueous $\mathrm{HCl}$ solution using ammonium persulphate as catalyst by following the method of Chaing and MacDiarmid [19]. Conducting polyaniline based paints were prepared by followinga similar techniquedeveloped by P.C. Deb and his coworkers [5] and elaborated below.The ingredients listed in the Table 1 were added after filtering to the solution of epoxy resin and the mixture was ball milled for $16 \mathrm{hrs}$ (Drive motor : Crompton Make - 2 HP, 1440 rpm 415 V, 50 Hz, FLP foot mounted motor along with gearbox U 287, 25:1 Shanthi Make : Ball Mill supplied by Indo German Industries, Daman, India). The purpose of adding $\mathrm{TiO}_{2}$ and Di-octylphthalate(DOP)in epoxy resin is to improve viscosity and elastic properties of paints .Xylene was used as a solvent for paint formulation. The paints were filtered through fine cotton and applied on the low carbon steel samples. The paint thickness on steel sample was maintained at $120 \pm 5 \mu \mathrm{m}$.

Table 1 Conducting polyaniline based paint ingredients

\begin{tabular}{|l|l|}
\hline Ingredients & Wt $\%$ \\
\hline Epoxy Resin $(\mathrm{GY} 250)$ & $100 \mathrm{gm}$ \\
\hline PANI-HCl $(1 \mathrm{~N} \mathrm{HCl})$ & 0.1 gmto $3.5 \mathrm{gm}$ \\
\hline $\mathrm{TiO}_{2}$ & $10 \mathrm{gm}$ \\
\hline DOP & $10 \mathrm{gm}$ \\
\hline Xylene & $10 \mathrm{gm}$ \\
\hline
\end{tabular}

\subsection{Corrosion Studies}

Acorrosion cellhaving three electrode geometry of paint coated sampleas working electrode $\left(8 \mathrm{~cm}^{2}\right)$,stainless steel as counter electrode and saturated calomel electrode (SCE) as a reference electrodewas used. The cell was coupled with Gamry Reference system 600 (Wilmington, USA) for impedance measurements. The EIS measurements were carried out under potentio-static conditions. The frequency was varied from $100 \mathrm{kHz}$ to $0.01 \mathrm{~Hz}$ using an A.C. excitation potential of $10 \mathrm{mV}$.

\section{RESULTS AND DISCUSSION}

\subsection{Open Circuit Potential Measurements}

The open circuit potential values provide supporting information to electrochemical impedance spectroscopy regarding the corrosion undergone by the steel during and after immersion. The evolution of OCP for PANI-HCl coated steel samples during immersion durations of 48 hours and 120 hours in $3.5 \% \mathrm{NaCl}$ solution was studied and thevalues are recorded in the Table 2. 
Table2.Open circuit potentials for 48 hours and 120 hours

\begin{tabular}{|l|l|l|l|}
\hline \multirow{2}{*}{$\begin{array}{l}\text { Wt\% of } \\
\text { Polyaniline }\end{array}$} & \multicolumn{3}{|l|}{ Open Circuit Potential $(\mathrm{mV})$} \\
\cline { 2 - 4 } & $0 \mathrm{hrs}$ & $48 \mathrm{hrs}$ & $120 \mathrm{hrs}$ \\
\hline 0.1 & -530 & -548 & -520 \\
\hline 0.5 & -521 & -544 & -515 \\
\hline 1.0 & -511 & -552 & -501 \\
\hline 1.5 & -513 & -548 & -502 \\
\hline 2.0 & -490 & -550 & -455 \\
\hline 2.5 & -482 & -537 & -530 \\
\hline 3.0 & -500 & -555 & -498 \\
\hline
\end{tabular}

A decreasing trend towards more -ve potential was observed for all painted samples from beginning to 48 hours. The rapid decrease in ocp can be attributed to absorption of water and ionic species such as $\mathrm{OH}^{-}$and $\mathrm{Cl}^{-}$etc at the paint/steel interface. Beyond this time period, a shift towards more +ve potential were recorded for all painted samples up to 120 hours. For instance, in case of 2.0 wt \% PANI-HCl coated steel sample, the ocp has decreased from $-490 \mathrm{mV}$ to -550 $\mathrm{mV}$ initially and has started to increase in the noble direction and has reached $-455 \mathrm{mV}$. This behavior can be assigned to the formation of passive layer on steel surface[7].

\subsection{Electrochemical Impedance Spectroscopy}

In the Electrochemical Impedance Spectroscopy, an electrode impedance is plotted as a function of applied frequency. UsingEIS to characterize a paint coated metal simultaneously measures two phenomena - 1) Deterioration of the organic coating caused by immersion in an electrolyte and - 2) Increase in corrosion rate of the underlying substrate due to the deterioration of the coating and subsequent attack by the electrolyte. EIS studies on polyaniline based painted low carbon steel samples were carried out in $3.5 \% \mathrm{NaCl}$ for 48 hours and 120 hours and reported here in terms of Bode plots. These plots were modelled by using appropraite equvalent circuits and quantititative data that relates to the quality of a paint coating on a metal was obtained.

\subsubsection{Immsersion upto 48 Hours}

The electrochemical behaviour of conducting polyaniline based painted low carbon steel samples in $3.5 \% \mathrm{NaCl}$ for 48 hours is shown in terms of Bode plots in the figures $1,2,3$ and 4 .

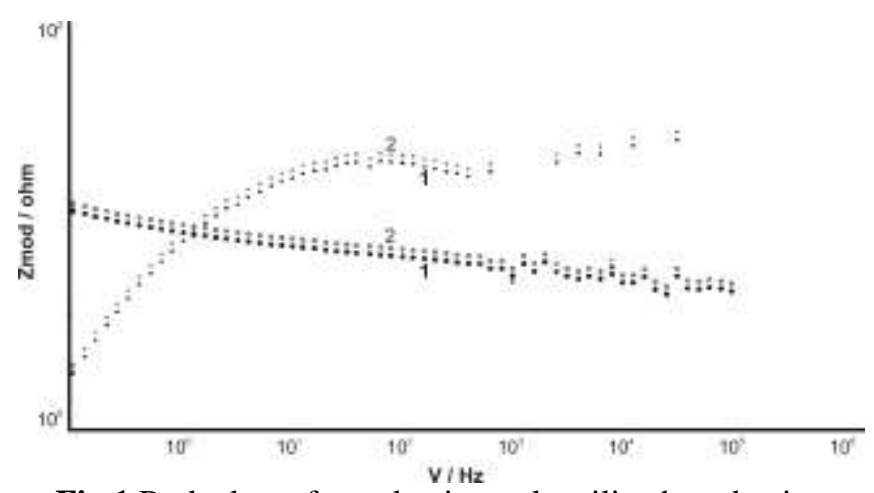

Fig.1 Bodeplots of conducting polyaniline based paint coated low carbon steel samples in $3.5 \% \mathrm{NaCl}(1-0.1$ wt $\%$ PANI, 2- $0.5 \mathrm{wt} \%$ PANI)

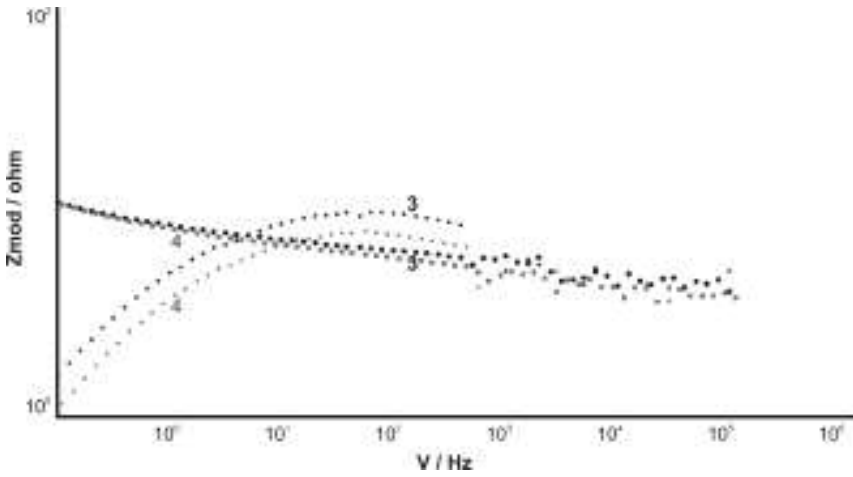

Fig. 2 Bodeplots of conducting polyaniline based paint coated low carbon steel samples in $3.5 \% \mathrm{NaCl}(3-1 \mathrm{wt} \%$ PANI, 4-1.5 wt\% PANI)

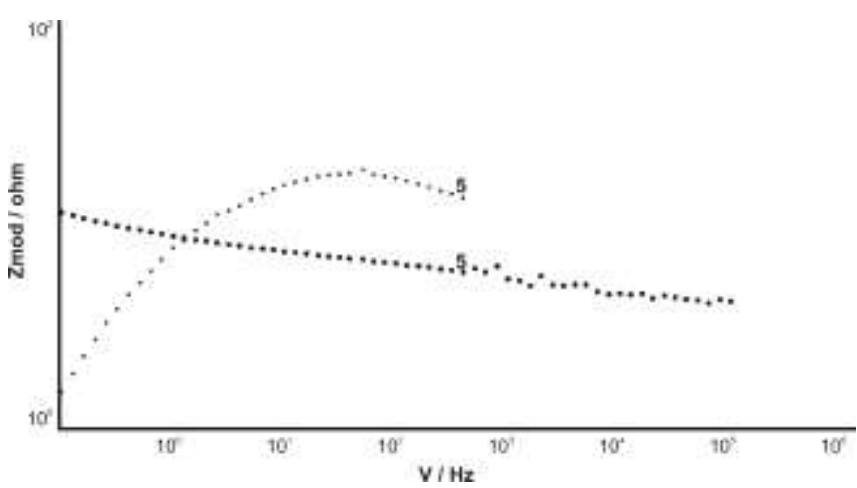

Fig. 3 Bodeplots of conducting polyaniline based paint coated low carbon steel samples in $3.5 \% \mathrm{NaCl}(5-2 \mathrm{wt}$ $\%$ PANI)

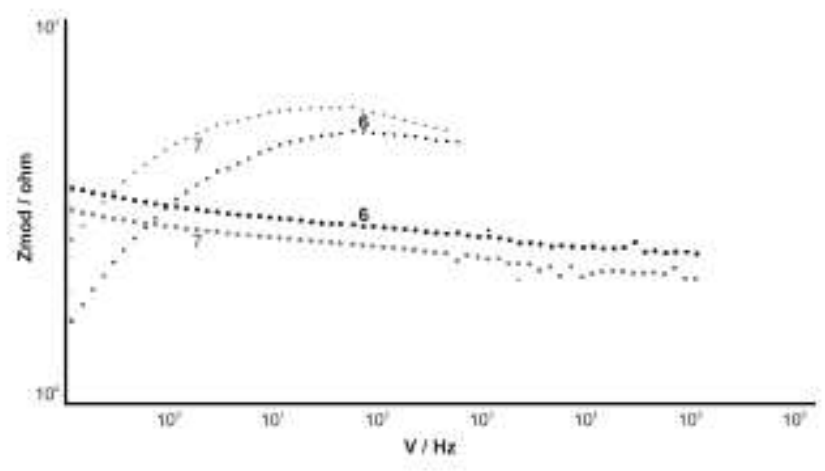

Fig.4 Bodeplots of conducting polyaniline based paint coated low carbon steel samples in $3.5 \% \mathrm{NaCl}(6-2.5 \mathrm{wt} \%$ PANI, 7 - 3wt $\%$ PANI)

\subsubsection{Immsersion Upto 120 Hours}

The electrochemical behaviour of conducting polyaniline based painted low carbon steel samples in $3.5 \% \mathrm{NaCl}$ for 120 hours is shown in terms of Bode plots in the figures 5,67 and 8 . 


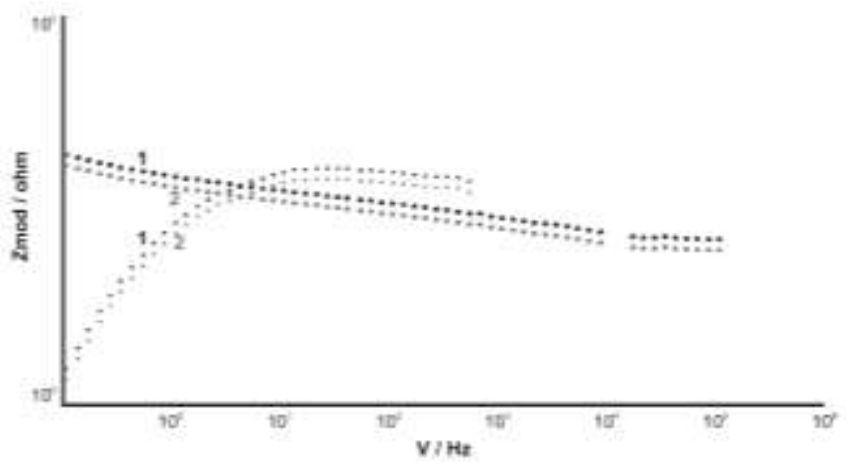

Fig. 5 Bodeplots of conducting polyaniline based paint coated low carbon steel samples in $3.5 \% \mathrm{NaCl}(1-0.5 \mathrm{wt} \%$ PANI, 2- 0.1 wt $\%$ PANI )

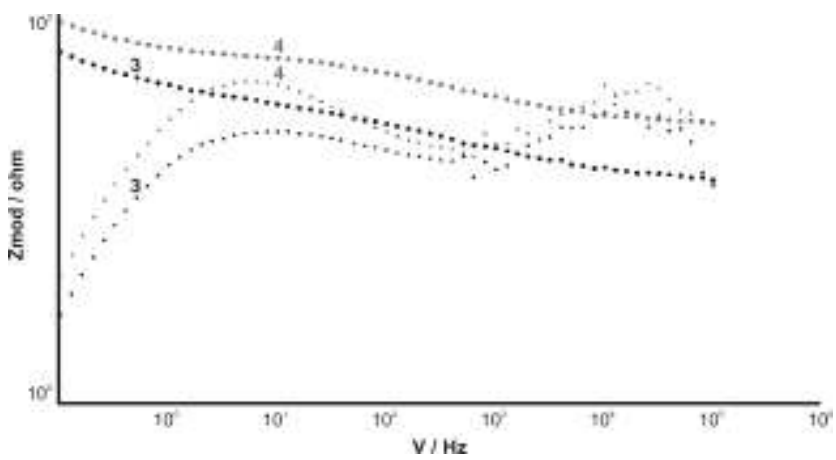

Fig. 6Bodeplots of conducting polyaniline based paint coated low carbon steel samples in $3.5 \% \mathrm{NaCl}(3-1 \mathrm{wt} \%$ PANI, $4-1.5 \mathrm{wt} \%$ PANI)

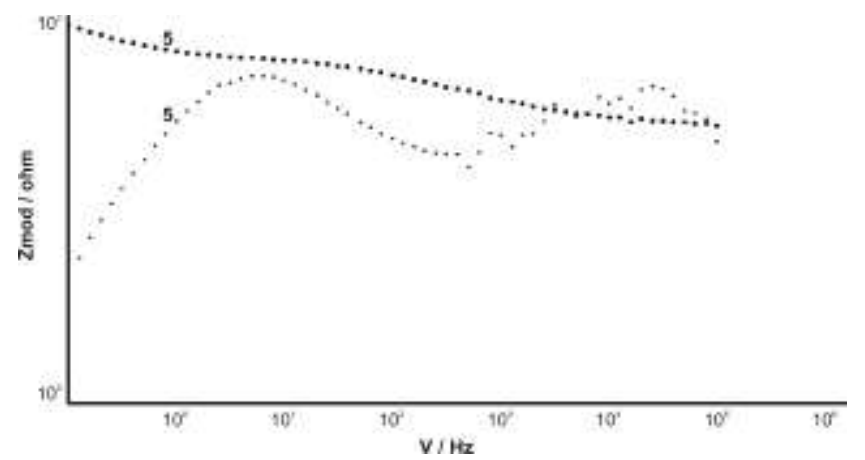

Fig. 7 Bodeplots of conducting polyaniline based paint coated low carbon steel samples in $3.5 \% \mathrm{NaCl}(5-2 \mathrm{wt} \%$ PANI)

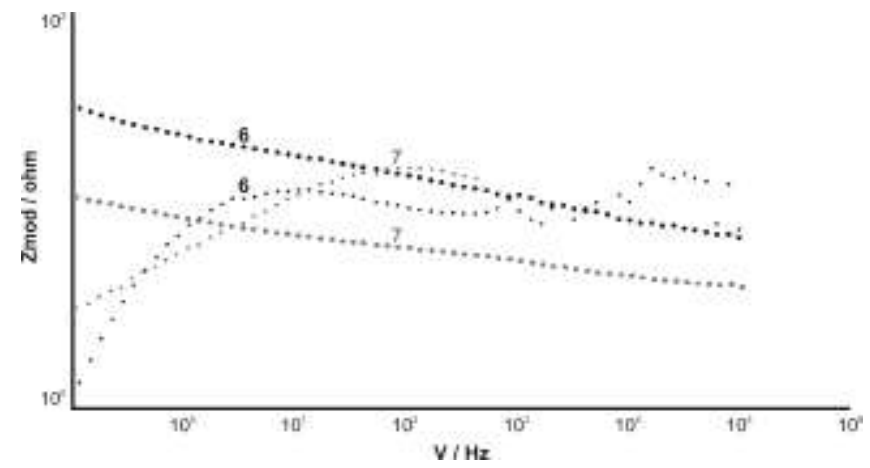

Fig. 8 :Bodeplots of conducting polyaniline based paint coated low carbon steel samples in $3.5 \% \mathrm{NaCl}(6-2.5 \mathrm{wt}$ $\%$ PANI, 7 - $3 \%$ PANI)
The data from the bode plots for $2 \mathrm{wt} \%$ PANI based paint coated steel in $3.5 \% \mathrm{NaCl}$ solution is shown in terms of Nyquest plot in the figure9.

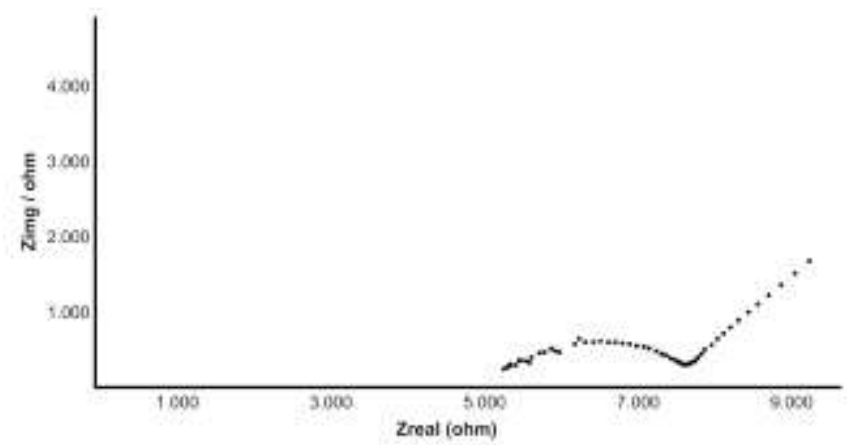

Fig 9: Nyquest plot of 2 wt $\%$ PANI based paint coated steel in $3.5 \mathrm{wt} \% \mathrm{NaClsolution.}$

The Nyquest plot, in case of $2 \mathrm{wt} \%$ PANI based paint coated steel, shows two components - a semicircle corresponding to high angular frequency range and the $45^{\circ}$ portion of the line corresponding to low angular frequency range. The first semicircle can be attributed to the coating performance and $45^{\circ}$ slope is characteristic of Warburg impedance. Appearance of an incomplete semicircle withwarburg impedance parameter reveals that the electrolyte has started to penetrate. This type of behavior is analyzed with the constant phase element with diffusional circuit, also known as the circuit with mixed kinetic and charge transfer control, is depicted infigure 10.

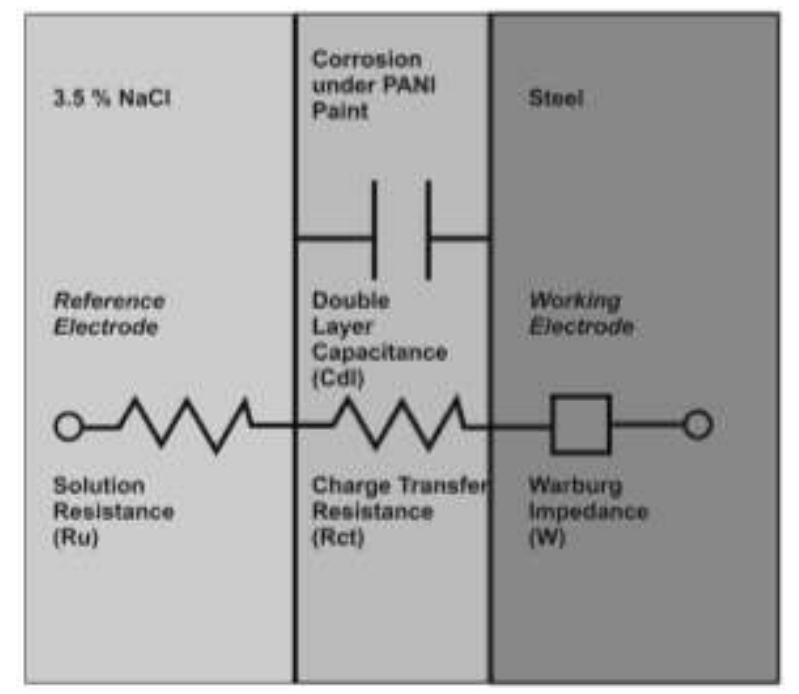

Fig.10: An equivalent circuit used for modeling impedance curves of painted immersed samples

As shown in the figure10, a diffusion impedance parameter known as Warburg impedance is included in the circuit series. $R_{U}$ is solution resistance, $C_{d l}$ is double layer capacitance, $R_{c t}$ is charge transfer resistance. To considerable extent it corresponds to polarization resistance. In case of steel in contact with aqueous solution, the following reaction occurs:

$$
\mathrm{Fe}=\mathrm{Fe}^{2+}+2 \mathrm{e}
$$


$\mathrm{Fe}{ }^{2+}$ ions diffuse into the electrolyte and the electrons migrate to the cathode through the steel producing corrosion current. Thus charge is being transferred when a metallic electrode comes in contact with electrolyte. The charge transfer resistance is the resistance for the ionic transport through the coating. The coating is not the only feature of the sample that gives rise to a capacitance. The double layer is generated as iron ions from the solution adhere to the electrode surface. There is a charge on the steel electrode and a charge in the electrolyte that are separated by the coated steel- electrolyte interface. The charged electrode is separated from the charged ions. The double layer possesses capacitance which is known as double layer capacitance. The double layer capacitance and the charge transfer resistance jointly represent electrochemistry of corrosion at the paint coating /steel interface after coating penetration by the corrosion species. The impedance parameters were obtained by using Gamry software by using constant phase element model (CPE) and recorded in the Table 4.

Table 4.Impedance parameters

\begin{tabular}{|c|c|c|c|}
\hline \multicolumn{4}{|l|}{$0.1 \mathrm{Wt} \%$} \\
\hline Parameters / Time & 0 hours & 48 hours & 120 hours \\
\hline $\mathrm{R}_{\mathrm{U}}\left(\mathrm{Ohm} \mathrm{cm}^{2}\right)$ & 1.1 & 3.2 & 1.6 \\
\hline $\mathrm{C}_{\mathrm{dl}}(\mu \mathrm{F})$ & 1.2 & 3.1 & 1.12 \\
\hline $\mathrm{R}_{\mathrm{ct}}\left(\mathrm{Ohm} \mathrm{\textrm {cm } ^ { 2 } )}\right.$ & 18.2 & 16.1 & 24.18 \\
\hline $\mathrm{W}_{\mathrm{d}}\left(\mathrm{Ohm} \mathrm{cm}^{2}\right)$ & 1.94 & 6.28 & 2.46 \\
\hline \multicolumn{4}{|l|}{$0.5 \mathrm{Wt} \%$} \\
\hline Parameters / Time & 0 hours & 48 hours & 120 hours \\
\hline $\mathrm{R}_{\mathrm{U}}\left(\mathrm{Ohm} \mathrm{\textrm {cm } ^ { 2 } )}\right.$ & 1.2 & 3.2 & 1.4 \\
\hline $\mathrm{C}_{\mathrm{dl}}(\mu \mathrm{F})$ & 1.3 & 3.98 & 1.76 \\
\hline $\mathrm{R}_{\mathrm{ct}}\left(\mathrm{Ohm} \mathrm{cm} \mathrm{cm}^{2}\right)$ & 21.05 & 15.04 & 26.27 \\
\hline $\mathrm{W}_{\mathrm{d}}\left(\mathrm{Ohm} \mathrm{cm}^{2}\right)$ & 1.97 & 6.30 & 2.47 \\
\hline \multicolumn{4}{|l|}{$1.0 \mathrm{Wt} \%$} \\
\hline $\mathrm{R}_{\mathrm{U}}\left(\mathrm{Ohm} \mathrm{cm}^{2}\right)$ & 1.28 & 3.589 & 1.8 \\
\hline $\mathrm{C}_{\mathrm{dl}}(\mu \mathrm{F})$ & 0.0038 & 3.98 & 1.25 \\
\hline $\mathrm{R}_{\mathrm{ct}}\left(\mathrm{Ohm} \mathrm{\textrm {cm } ^ { 2 } )}\right.$ & 80.62 & 12.1 & 34.54 \\
\hline $\mathrm{W}_{\mathrm{d}}\left(\mathrm{Ohm} \mathrm{cm}^{2}\right)$ & 0.076 & 2.51 & 1.61 \\
\hline \multicolumn{4}{|l|}{$1.5 \mathrm{Wt} \%$} \\
\hline $\mathrm{R}_{\mathrm{U}}\left(\mathrm{Ohm} \mathrm{cm}^{2}\right)$ & 1.48 & 3.4 & 4.83 \\
\hline $\mathrm{C}_{\mathrm{dl}}(\mu \mathrm{F})$ & 0.0075 & 6.20 & 1.35 \\
\hline $\mathrm{R}_{\mathrm{ct}}\left(\mathrm{Ohm} \mathrm{\textrm {cm } ^ { 2 } )}\right.$ & 90.60 & 19.34 & 37.29 \\
\hline $\mathrm{W}_{\mathrm{d}}\left(\mathrm{Ohm} \mathrm{cm}^{2}\right)$ & 0.090 & 3.14 & 0.13 \\
\hline \multicolumn{4}{|l|}{$2 \mathrm{Wt} \%$} \\
\hline $\mathrm{R}_{\mathrm{U}}\left(\mathrm{Ohm} \mathrm{\textrm {cm } ^ { 2 } )}\right.$ & 1.444 & 3.42 & 4.87 \\
\hline $\mathrm{C}_{\mathrm{dl}}(\mu \mathrm{F})$ & 0.0053 & 6.70 & 1.52 \\
\hline $\mathrm{R}_{\mathrm{ct}}\left(\mathrm{Ohm} \mathrm{cm} \mathrm{cm}^{2}\right)$ & 79.85 & 2.5 & 41.20 \\
\hline $\mathrm{W}_{\mathrm{d}}\left(\mathrm{Ohm} \mathrm{cm}^{2}\right)$ & 0.083 & 1.36 & 0.14 \\
\hline \multicolumn{4}{|l|}{$2.5 \mathrm{Wt} \%$} \\
\hline $\mathrm{R}_{\mathrm{U}}\left(\mathrm{Ohm} \mathrm{\textrm {cm } ^ { 2 } )}\right.$ & 35.09 & 3.62 & 20.15 \\
\hline $\mathrm{C}_{\mathrm{dl}}(\mu \mathrm{F})$ & 0.0094 & 3.11 & 1.21 \\
\hline $\mathrm{R}_{\mathrm{ct}}\left(\mathrm{Ohm} \mathrm{\textrm {cm } ^ { 2 } )}\right.$ & 119.57 & 13.27 & 27.74 \\
\hline $\mathrm{W}_{\mathrm{d}}\left(\mathrm{Ohm} \mathrm{cm}^{2}\right)$ & 0.096 & 5.31 & 3.80 \\
\hline \multicolumn{4}{|l|}{$3.0 \mathrm{Wt} \%$} \\
\hline $\mathrm{R}_{\mathrm{U}}\left(\mathrm{Ohm} \mathrm{\textrm {cm } ^ { 2 } )}\right.$ & 1.80 & 4.2 & 1.87 \\
\hline $\mathrm{C}_{\mathrm{dl}}(\mu \mathrm{F})$ & 0.0047 & 8.70 & 3.38 \\
\hline $\mathrm{R}_{\mathrm{ct}}\left(\mathrm{Ohm} \mathrm{cm} \mathrm{cm}^{2}\right)$ & 58.11 & 4.029 & 20.19 \\
\hline $\mathrm{W}_{\mathrm{d}} \mathrm{Ohm} \mathrm{cm}^{2}$ & 0.081 & 5.4 & 1.97 \\
\hline
\end{tabular}

It can be seen that the charge transfer resistance value $\left(\mathrm{R}_{\mathrm{ct}}\right)$ is decreased upto 48 hours of immersion and subsequently increased upto 120 hours of immersionin case of all conducting PANI based painted samples. The initial decrease of $R_{c t}$ may be due to dissolution of iron but subsequent possible formation of passive $\mathrm{Fe}_{2} \mathrm{O}_{3}$ layer might have caused an increase in $\mathrm{R}_{\mathrm{ct}}$ value [7]. This reveals, ultimately, effective barrier protection of coating even after immersion of 120 hours. It is to be noted that warburg impedance parameter gets increased up to 48 hours and subsequently decreases. It can also be observed that double layer capacitance values initially increased after 48 hours of immersion, but after 120 hours, it goes on decreasing in case of all conducting PANI based painted samples. The initial increase can be assigned to double layer formation between metal and coating. In case of 2 wt $\%$ PANI based painted sample, the double layer capacitance which was initially $0.0053 \mu$ Fincreased up to $6.70 \mu$ Fafter 48 hours and reaches to the order of $1.52 \mu \mathrm{F}$ after 120 hours of immersion. Also, the charge transfer resistance which was initially $79.85 \mathrm{ohm}$ $\mathrm{cm}^{2}$ decreased upto 2.5 ohm $\mathrm{cm}^{2}$ within 48 hours and subsequently increased upto $41.20 \mathrm{ohm} \mathrm{cm}^{2}$ during 120 hours of immersion. This confirms more protective nature of $2 \%$ wtPANI based paint coating even after 120 hours of immersion as compared to other paint compositions used in this work. In case of traditional paint coatings, the resistance of the paint coating will decease and the capacitance of the film will increase as a function of time. This fact is generally explained on the basis of water ingress leading to swelling in the coating and causing an increase of the ionic barrier properties. The role of polyaniline in corrosion prevention can be explained on the basis of its ability to intercept electrons at the steel surface and to transport them to the outside of the coating. For this action to begin, certain electrochemical activity at the metal surface has to be initiated and will be achieved as soon as water and corrosive ions diffuse through the coating and contact the steel surface The presence of the oxygen concentration gradient across the coating on the one hand and restricted flow of electrons at the steel surface on the other hand is decisive in the spatial separation of the cathodic and anodic partial reactions. In addition, the cathodic reaction gets displaced outside of the steel substrate. Such a displacement results in a formation of $\mathrm{OH}$ - ions at interface as schematically shown in figure 11 .

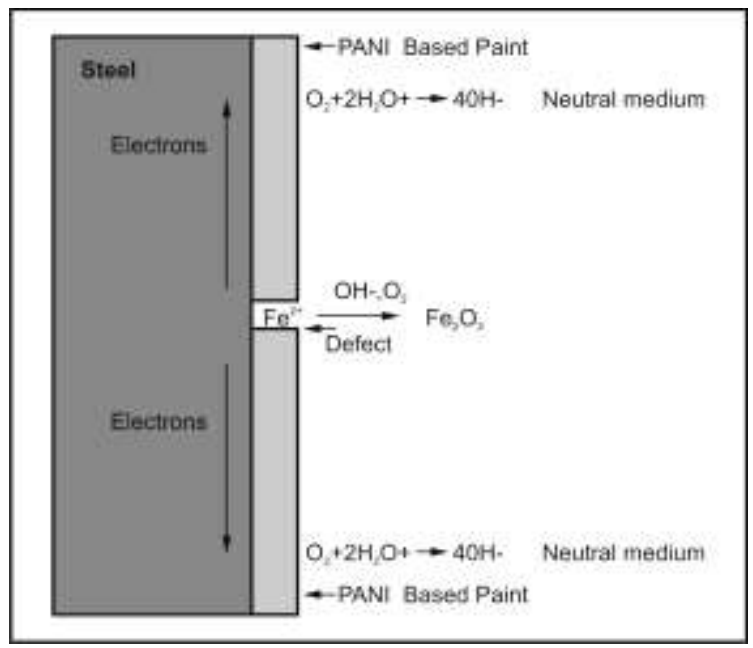

Fig 11: Passivation of steel by poyaniline based paint coating. 
In addition to the oxygen reduction, oxidation of the ferrous ions to ferrous oxides takes place on the exposed steel surface at defect and under the paint coating in neutral medium. As a result of the separation of partial reactions, conditions at the steel interface become more favorable for the maintenance of its passive state and formation of stable oxides [20].

\section{CONCLUSION}

The anticorrosion performance of conducting polyaniline based paint on low carbon steel has been investigated in 3.5 $\% \mathrm{NaCl}$ by electrochemical impedance spectroscopy. Investigations have shown the conducting polyaniline based paint is corrosion resistive in neutral medium. It protects under lying steel surface by passivation.

\section{ACKNOWLEDGEMENT}

The author is thankful to Prof. Dr. C. B. Bangal, Director RMD Singhad Technical Institutes Campus, Warje-Pune \& Prof. Dr. R. S. Khairnar, Director, School of Physical Sciences, S. R. T. M. University for providing necessary facilities for the work and for encouragement. Also authors would like to thank Dr. P. P. Deshpande, Associate Prof. COE, Pune \& A. B. Samuai, Director, NMRL, AmbarnathThane for valuable guidance during the research.

\section{REFERENCES}

[1] Ahmad N., Mac Diarmid A.G., Synthetic Metals, 1996, vol. 78, p.103.

[2] Deshpande P.P. ,Peshwe D.R, Pathak S.U, J. Institution of Engineers (India), 2001, vol. 82, p.33.

[3] Deshpande P.P., Peshwe D.R., Pathak S.U., Trans. Indian Inst. Met., 2001, vol.4, p.179.

[4] Talo A., Passiniemi P. ,Forsen O. , Ylasaari S.Y., Synth. Metals, 1997, 85, p.1333.

[5] Samui A.B., Patankar A.S., Ragarajan J, Deb P.C., Progress Org. Coatings, 2003, vol. 47,p.1.

[6] Rout T.K.,Jha G., Singh A.K., Bandyopadhya, Mohanty O.N, Surface and Coatings Technology , 2003, p16.

[7] Sathiyanarayanan S., Muthukrishnan S., Venkatachari G., Trivedi D.C., Progress Org. Coatings, 2005, p. 297.

[8] Samui A.B., Phadnis S.M., Progress Org. Coatings, 2005, vol. 54, p. 263.

[9] Laco J.I.I., Villota F.C., Mestres F.L., Progress Org. Coatings ,2005, vol.52, p.151.

[10] Syed Azim S. , Sathiyanarayanan S., Venkatachari G., Progress Org. Coatings, 2006, p. 154.

[11] Meroufel A., Deslouis C., Touzain S., Electro chim. Acta, 2008, vol.53, p.2331.

[12] Kalendova A., Sapurina I., Stejskal J., Vesely D., Corrosion Science, 2008, vol 50 p3549.

[13] Armelin E, Aleman C., Iribarren J.I., Progress Org. Coatings, 2009, vol. 65, p.88.

[14] Armelin E., Meneguzzi A., Ferreira C.A, Aleman C., Surf. Coat. Tech. 2009, vol.203, p.3763.
[15] Kamaraj K., Sathiyanarayanan S, Muthukrishnan S., Venkatachari G., Progress Org. Coatings ,2009, vol. 64, p. 460 .

[16] Sathiyanarayanan S., Jeyaram R., Muthukrishnan S., Venkatachari G, J. Electrochem. Soc. 2009, vol.156, p.127.

[17] Sathiyanarayanan S, Karpakam K., Kamraj K., Muthukrishnan S., Venkatachari G., Surface and Coatings Technology, 2010, vol. 204 , p 1426.

[18] Deshpande P.P., Jagtap S.P., More M.A. , Khairnar R.S., J. Electro chem. Soc. (India) 2008, vol.57,p. 83.

[19] Chaing J.C., MacDiarmid A.G., Synthetic Metals, 1986, vol.13, p.193.

[20] Schauer T., Joos A., Dulong L., Eisenbach C.D., Progress Org. Coatings, 1998, vol. 33, p. 25. 